\title{
Study of planter grasp in neonates with hypoxic ischemic encephalopathy
}

\author{
Sagaraia KK ${ }^{1}$, Patel $\mathrm{SK}^{2}, \operatorname{Rao}^{3} \mathrm{SK}^{3}, \operatorname{Singh} \mathbf{J}^{4}, \operatorname{Singh~HP}^{5}$ \\ ${ }^{1}$ Dr Kamal Kishor Sagaraia, Post Graduate student, ${ }^{2}$ Dr Saurabh Kumar Patel, Post Graduate student, ${ }^{3}$ Dr. S.K. Rao, \\ Assistant Professor, ${ }^{4}$ Dr. Jyoti Singh, Associate Professor, ${ }^{5}$ Dr H P Singh, Professor \& Head. All are affiliated with \\ Department of Paediatrics, Gandhi Memorial Hospital, Shyam Shah Medical College, APS University, Rewa, MP, India.
}

Address for Correspondence: Dr Saurabh Kumar Patel, Post Graduate Student, Department of Pediatrics, Gandhi Memorial Hospital, Shyam Shah Medical College, APS University, Rewa.MP. India.

Postal Address- 6/450 Shivnath Bhawan, Bansghat, near old Bus-Stand, Rewa (M.P.), e-maildr.patelsaurabh@gmail.com

\begin{abstract}
Introduction: Assessment of primitive reflexes is one of the earliest, simplest and most frequently used assessment tool for neurological status of newborns. Hypoxic ischemic encephalopathy (HIE) is a common cause of neurological morbidity in neonatal period. Aims and Objective: To Study association of planter grasp and its latency and total duration in neonates with HIE. Material and methods: It is an observational, cross sectional study. 145 new born fulfilling criteria of HIE according to Sarnath and Sarnath classification, admitted in the neonatal intensive care unit of S.S. medical college over a period of one year were included. Planter grasp was elicited from 12 hours after birth to 72 hours of birth. Video recording was done simultaneously, and the investigator analyzed the video-clippings and calculated the various parameters with the help of a stop watch with accuracy of 1/100 of a second. Result: Planter grasp was not elicitable in $16.43 \%$ of HIE-I, 55\% of HIE-II and $83.33 \%$ of HIE-III newborns. The latency of Plantar grasp was found to be 0.696 seconds ( $\mathrm{sec}$ ) for HEI-I, $1.689 \mathrm{sec}$ for HIE-II and $0.994 \mathrm{sec}$ for HIE-III and total duration for completion was $1.385 \mathrm{sec}$ for HIE-I, $3.139 \mathrm{sec}$ for HIE -II and $1.858 \mathrm{sec}$ for HIE-III. Conclusion: Absence of planter grasp can be correlated with the increase in severity of HIE. There is significant difference in latency interval and total duration of planter response in different stages of HIE. Detailed examination of primitive reflexes can add in the diagnosis, prognosis and early intervention of high risk newborn especially in resource limited setting where EEG and other neuroimaging facilities are not readily available.
\end{abstract}

Key words: HIE, Newborns, Planter Grasp

\section{Introduction}

Knowledge of the ability of the newborn and of his primitive reflexes is important not only for the understanding of human development as a whole but also for overall assessment of a baby and recognition of possible neurological damage in various conditions present in neonatal period. Hypoxic ischemic encephalopathy (HIE) in the perinatal period is one such important cause of neurological manifestation in the newborn. Primitive reflexes are brainstem-mediated, automatic movements which may begin as early gestation week 25-26, and which are fully present at

Manuscript received: $23^{\text {rd }}$ Oct 2015

Reviewed: $30^{\text {th }}$ Oct 2015

Author Corrected: $9^{\text {th }}$ Nov 2015

Accepted for Publication: $18^{\text {th }}$ Nov 2015 birth in term newborns [1, 2]. Assessment of these reflexes is one of the earliest, simplest, and most frequently used assessment tools among health care providers for newborns and young infants [2]. Persistent, vigorous, weak, or unsymmetrical responses are closely-linked with neurological impairment in full term and high-risk newborns [2,3]. However, very few data exist for high-risk infants in this topic. Among the various primitive reflexes, this study was undertaken particularly to describe the planter grasp in newborn with hypoxic ischemic encephalopathy (HIE) and to explore its association with different grades of HIE and to the best of our knowledge this is the first work to study planter grasp in patients of HIE. 


\section{Material and Methods}

This is an observational, cross sectional study. A total of 145 newborn with gestation age > 36 weeks with Hypoxic ischemic encephalopathy admitted in Neonatal intensive care unit (NICU), Department of Pediatrics, Shyam Shah Medical College, Rewa (M.P.), from September 2012 and August 2013 were included. Infants < 36 weeks, those who had congenital abnormalities and encephalopathy other than HIE were excluded from the study. Detailed antenatal and natal history of the mother was obtained.

Sarnath and Sarnath criteria [4] was used for classification of HIE after 12 hours of birth to 72 hours of birth. Stage 1 was defined by hyperalertness, uninhibited Moro reflexes and sympathetic effects; Stage 2 was marked by obtundation, hypotonia, strong distal flexion with or without seizures. Infants in stage 3 were stuporous, flaccid, and brain stem and autonomic functions were suppressed. We have not studied different stages of HIE in the same infant, each case was studied only once and categorized in relevant group. Planter grasp was examined and video recording was done simultaneously, and the investigator analyzed the video-clippings and calculated the various parameters with the help of a stop watch with accuracy of $1 / 100$ of a second. Mean values were calculated for latency interval and total duration of response. Upper and lower limit was obtained by calculating the $95 \%$ confidence interval for the means. Plantar grasp was examined by keeping the child in supine position and pressing a thumb against the sole just behind the toes in the foot which results in flexion of toes [5]. Latency was defined as duration between touching of the feet and initiation of the movement and total duration was the time delay between touching the feet and end of flexion movement of toes, while the examiners finger still in place. The study was approved by the Ethics Committee of the College, and informed consent was obtained from the parents of all patients

\section{Result}

Out of total 145 newborns 73 had HIE stage I, 60 HIE stage II and 12 had HIE stage III during examination. Most of the newborn $(98.6 \%)$ born from the mother aged 18 - 35 years, 62 were primipara and 83 were multipara. In our study most of the newborn were male $(72.4 \%)$. Most foetuses had normal vertex presentation (93.1\%), born by normal vaginal delivery $(85.5 \%)$ and were appropriates for gestational age $(90.3 \%)$, other things are detailed in table 1 and 2.

Table 1: General sample Characteristics of mother

\begin{tabular}{|c|c|c|c|c|c|}
\hline $\begin{array}{c}\text { Maternal Age } \\
\text { (Years) }\end{array}$ & $\begin{array}{c}\text { Number } \\
\text { (Percentage) }\end{array}$ & Sex & $\begin{array}{c}\text { Number } \\
\text { (Percentage) }\end{array}$ & Parity & $\begin{array}{c}\text { Number } \\
\text { (Percentage) }\end{array}$ \\
\hline $\mathbf{1 8 - 3 5}$ & $143(98.6 \%)$ & Male & $105(72.4)$ & Primii & $62(42.8 \%)$ \\
\hline$>\mathbf{3 5}$ & $2(1.4 \%)$ & Female & $40(27.6)$ & Multipara & $83(57.2)$ \\
\hline
\end{tabular}

Table 2: General sample Characteristics of newborns

\begin{tabular}{|l|c|c|c|c|c|}
\hline Presentation & $\begin{array}{c}\text { Number } \\
\text { (Percentage) }\end{array}$ & Type of birth & $\begin{array}{c}\text { Number } \\
\text { (Percentage) }\end{array}$ & Fetal Growth & $\begin{array}{c}\text { Number } \\
\text { (Percentage) }\end{array}$ \\
\hline Vertex & $135(93.1)$ & $\begin{array}{c}\text { Normal vaginal } \\
\text { Delivery }\end{array}$ & $124(85.5)$ & $\begin{array}{c}\text { Appropriate for } \\
\text { gestational age }\end{array}$ & $131(90.3)$ \\
\hline Breech & $8(5.5)$ & $\begin{array}{c}\text { Assisted vaginal } \\
\text { Delivery }\end{array}$ & $7(4.8)$ & $\begin{array}{c}\text { Small for } \\
\text { gestational age }\end{array}$ & $12(8.3)$ \\
\hline Transverse & $1(.7)$ & $\begin{array}{c}\text { Lowes Section } \\
\text { Cessarian Section } \\
\text { (LSCS) }\end{array}$ & $14(9.7)$ & $\begin{array}{c}\text { Large for } \\
\text { gestational age }\end{array}$ & $2(1.4)$ \\
\hline Face & $1(.7)$ & & & & \\
\hline
\end{tabular}

Table- 3: Asphyxiated newborns on the basis of presence or absence of Planter Grasp

\begin{tabular}{|l|c|c|c|c|c|c|}
\hline \multirow{2}{*}{ Reflex } & \multicolumn{2}{|c|}{ HIE-I (N=73) } & \multicolumn{2}{c|}{ HIE-II (N=60) } & \multicolumn{2}{c|}{ HIE-III (N=12) } \\
\cline { 2 - 7 } & Eliciated & Not eliciated & Eliciated & Not eliciated & Eliciated & Not eliciated \\
\hline Planter grasp & $61(83.56 \%)$ & $12(16.43 \%)$ & $27(45 \%)$ & $33(55 \%)$ & $2(16.67)$ & $10(83.33 \%)$ \\
\hline
\end{tabular}


Table 4: Duration of Latency and Completion of Planter grasp

\begin{tabular}{|c|c|c|}
\hline HIE grade & $\begin{array}{c}\text { Initiation } \\
\text { (mean in seconds) }\end{array}$ & $\begin{array}{c}\text { Completion } \\
\text { (mean in seconds) }\end{array}$ \\
\hline $\begin{array}{c}\text { HIE-I } \\
\mathbf{N}=\mathbf{7 3}\end{array}$ & 0.696131148 & 1.385081967 \\
\hline $\begin{array}{c}\text { HIE-II } \\
\mathbf{N}=\mathbf{6 0}\end{array}$ & 1.689296296 & 3.13884 \\
\hline $\begin{array}{c}\text { HIE-III } \\
\text { N=12 }\end{array}$ & 0.994 & 1.8575 \\
\hline P-value & 0.0005 & $<0.0001$ \\
\hline
\end{tabular}

Planter grasp was not elicitable in $16.43 \%$ of HIE stage I, 55\% of HIE stage II and $83.33 \%$ of HIE stage III newborns. The latency of Plantar grasp was found to be 0.696 seconds (sec) for HEI-I, $1.689 \mathrm{sec}$ for HIE-II and 0.994 sec for HIEIII and total duration for completion was $1.385 \mathrm{sec}$ for HIE-I, $3.139 \mathrm{sec}$ for HIE -II and $1.858 \mathrm{sec}$ for HIE-III.

\section{Discussion}

On one hand Improved antenatal care and institutional deliveries has resulted in decreased mortality on the other hand there is increase in responsibilities of the health care providers to prevent morbidity. Failure to initiate and sustain breathing immediately after delivery has been associated with hypoxic ischemic injury to the central nervous system (CNS) and the clinical manifestations of this injury have been termed as Hypoxic Ischemic Encephalopathy (HIE). The incidence of HIE in developed countries is estimated to be 1.5 per 1,000 live births [6].

Estimates in developing countries range from 2.3-26.5 per 1,000 live births $[7,8]$. The localization and extent of perinatal hypoxic-ischemic cerebral injury is determined principally by the maturity of the brain at the time of insult and the severity and duration of the insult [9]. The normal presence or absence of neonatal reflexes is related to the neurological status of the newborns. In the present work we tried to evaluate the status of planter grasp in different stages of HIE.

We evaluated all infants after 12 hours of birth to overcome the effect of stress due to delivery and proper manifestation of clinical signs of HIE. Evaluation was done up to 72 hours as symptoms of HIE usually evolve over a period of 72 hours [4].

Of total 145 cases examined 73 (50.34\%) fell into HIE stage I, $60(41.37 \%)$ in HIE stage II and remaining 12 $(8.27 \%)$ in HIE stage III. Normally neonates in HIE stage I are hyper alert and have uninhibited Moro and stretch reflexes, In HIE stage II lethargic and week primitive reflexes, in HIE stage III comatose / stuporous and absent primitive reflexes [4]. In our study out of 73 neonates in HIE stage I, planter grasp was elicitable in $61(83.56 \%)$ and in remaining $12(16.43 \%)$ it could not be elicited. For uniformity we checked planter grasp over right foot but among non elicitable group we checked it on both side and in all cases it remained same i.e. non elicitable. Similarly it remain non elicitable in $55 \%$ and more than $80 \%$ in HIE stages II and III respectively. Many workers have also noted that abnormality of plantar grasp reflex is of high clinical significance $[10,11]$.

Same authors followed these patients with abnormal planter grasp and found its significant association with many neurological conditions presenting later in life including cerebral palsy $[12,13,14,15]$. We could not do follow up study in as most of our patients were lost to follow up, due to many reasons but mainly financial constrain of the family.

Studies on duration and quality of different events in normal response of planter grasp like the latency interval and total duration of reflex response are few, and standard values for these durations are not available [16]. Among all the cases of elicitable planter grasp response we tried to obtain latency interval and total duration of the response.

Latency and duration of completion both were maximum in HIE stage II, Total duration was least in HIE stage I but duration from initiation to completion was least in HIE stage III. The latency and total duration was significantly different in each group and this difference is due to severity and duration of hypoxic ischemic injury to different parts of the brain.

There are many limitations of our study as we have not record electroencephalography (EEG) due to limited resources, infant may be in transition phases of HIE, no follow up was done, we have accrued consecutive 
samples and no formal sample size calculations were done and abnormality detected may be normal variant of neonatal reflexes.

The strengths of our study are as follows: being the first study to show the association of planter grasp in the patients with HIE; sampling of all consecutive patients admitted to NICU, thus making selection bias less likely; exclusion of causes of encephalppathy other than HIE making results more disease specific.

There is significant difference in latency interval and total duration of planter response in different stages of HIE. Absence of planter grasp can be correlated with the increase in severity of HIE. This absence of planter grasp may be indicator of spasticity and such high risk infant should be followed for early diagnosis and intervention if needed.

Detailed neurological examination including examination of primitive reflexes can add in the diagnosis, prognosis and early intervention of high risk newborn especially in resource limited setting where EEG and other neuroimaging facilities are not readily available. Although there are many limitations of the study but its result can be disseminated for further studies in similar and related field.

\section{Acknowledgements}

KKS and SKP collected the data and followed the case under the supervision of SKR and written the first draft of manuscript. SKR helped in writing the first draft. JS and HPS conceived and supervised the study and finalized the manuscript and will be the guarantors.

\section{Declarations}

Ethical approval: Obtained from Institutional Ethics Committee (Human Studies)

Funding: No funding sources.

Conflict of Interest: The authors declare no conflict of interest.

\section{References}

1. Gardner SL, Carter BS, Enzman-Hines MI, Hernandez JA. Merenstein \& Gardener's Handbook of Neonatal Intensive Care. New York: Mosby; 2011. 2.

2. Zafeiriou DI. Primitive reflexes and postural reactions in the neurodevelopmental examination. Pediatr Neurol. 2004 Jul;31(1):1-8.
3. Capute AJ, Accardo PJ, Vining EP, Rubenstein JE, Walcher JR, Harryman S, Ross A. Primitive reflex profile. A pilot study. Phys Ther. 1978 Sep;58(9):10615.

4. Sarnat HB, MS. Neonatal encephalopathy following fetal distress. A clinical and electroencephalographic study.

Arch Neurol. 1976 Oct;33(10):696-705.

5. Volpe JJ. Neurology of the newborn. Philadelphia: WB Saunders, 2001.

6. Schott JM, Rossor MN. The grasp and other primitive reflexes. J Neurol Neurosurg Psychiatry. 2003 May;74(5):558-60.

7. Kurinczuk JJ, White-Koning M, Badawi N. Epidemiology of neonatal encephalopathy and hypoxicischaemic encephalopathy. Early Hum Dev. 2010 Jun; 86(6):329-38. doi: 10.1016/j.earlhumdev.2010.05.010. Epub 2010 Jun 16.

8. Lawn JE, Lee AC, Kinney M, Sibley L, Carlo WA, Paul VK, Pattinson R, Darmstadt GL. Two million intrapartum-related stillbirths and neonatal deaths: where, why, and what can be done? Int J Gynaecol Obstet. 2009 Oct;107 Suppl 1:S5-18, S19. doi: 10.1016/j.ijgo.2009.07.016.

9. Horn AR, Swingler GH, Myer L, Harrison MC, Linley LL, Nelson C, Tooke L, Rhoda NR, Robertson NJ. Defining hypoxic ischemic encephalopathy in newborn infants: benchmarking in a South African population. J Perinat Med. 2013 Mar;41(2):211-7.

10. Futagi Y, Suzuki Y. Neural mechanism and clinical significance of the plantar grasp reflex in infants. Pediatr Neurol. 2010 Aug;43(2): 81-6. doi: 10.1016/j.pediatrneurol.2010.04.002.

11. Zafeiriou DI. Plantar grasp reflex in high-risk infants during the first year of life. Pediatr Neurol. 2000 Jan;22(1):75-6.

12. Futagi $Y$, Tagawa $T$, Otani K. Primitive reflex profile in infants: differences based on neurological abnormality. Brain Dev.1992 Sep;14 (5):294-8

13. Zafeiriou DI, Tsikoulas IG, Kremenopoulos GM. Prospective follow-up of primitive reflex profiles in 
high-risk infants: clues to an early diagnosis of cerebral palsy. Pediatr Neurol. 1995 Sep;13(2):148-52.

14. Zafeiriou DI, Tsikoulas IG, Kremenopoulos GM, Kontopoulos EE. Plantar response profile of highrisk infants at one year of life. J Child Neurol. 1999 Aug;14(8):514-7.
15. Futagi Y, Suzuki Y, Goto M. Clinical significance of plantar grasp response in infants. Pediatr Neurol. 1999 Feb;20(2):111-5.

16. Futagi Y, Toribe Y, Suzuki Y. The grasp reflex and moro reflex in infants: hierarchy of primitive reflex response. Int $\mathrm{J}$ Pediatr. 2012;2012:191562. doi: 10.1155/2012/191562. Epub 2012 Jun 11.

\section{How to cite this article?}

Sagaraia KK, Patel SK, Rao SK, Singh J, Singh HP. Study of planter grasp in neonates with hypoxic ischemic encephalopathy. Pediatr Rev: Int J Pediatr Res 2015;2(4):67-71.doi:10.17511/ijpr.2015.i04.06 